\title{
Clinical effectiveness of therapy with continuous- flow left ventricular assist devices in nonischemic versus ischemic cardiomyopathy: a systematic review and meta-analysis
}

\author{
Christopher Wavell, BSc \\ Andrew Sokolowski, BSc \\ Michelle L. Klingel, MSc \\ Charles Yin, PhD
}

A. Dave Nagpal, MD MSc

Results of this systematic review have previously been presented at the Schulich School of Medicine and Dentistry 2018 Cardiac Surgery Research Day, Nov. 12, 2018, London, Ont.

Accepted Feb. 19, 2020

\section{Correspondence to:}

D. Nagpal

B6-104 University Hospital

339 Windermere $\mathrm{Rd}$

London ON N6A 5A5

dave.nagpal@Ihsc.on.ca

DOI: $10.1503 /$ cjs.005719
Background: Clinicians may be less inclined to consider long-term left ventricular assist device (LVAD) therapy in end-stage heart failure (ESHF) as a result of nonischemic cardiomyopathy (NICM) versus ischemic cardiomyopathy (ICM) owing to potentially greater right ventricular involvement in the former; however, it is unknown whether the cause of heart failure has a clinically meaningful effect on outcomes following LVAD implantation. In this systematic review, we aimed to determine whether ischemic versus nonischemic etiology has any impact on patientrelevant outcomes.

Methods: We searched MEDLINE, Embase, PubMed and the Cochrane Library for studies published in English between Jan. 1, 2000, and Nov. 22, 2018, that examined survival and transplantation rates following LVAD implantation in patients with NICM or ICM. Randomized clinical trials, cohort studies, case-control studies, cross-sectional studies and case series with a sample size of at least 8 patients were eligible for inclusion. To be included in the meta-analysis, outcomes had to include at least death reported at 30 days or 1 year after LVAD implantation. Quality of included studies was assessed by 2 independent reviewers using the NewcastleOttawa Quality Assessment Scale for Cohort Studies. The Grading of Recommendations Assessment, Development and Evaluation (GRADE) quality-assessment tool was used to assess outcomes (30-d survival, 1-yr survival and cardiac transplantation following LVAD therapy) across studies.

Results: From a total of 2843 citations identified, 7 studies met all inclusion criteria. Studies were generally of good quality, but reporting of patient demographic characteristics, outcomes and complications was heterogeneous. We found no significant difference in 30-day or 1-year survival or in cardiac transplantation rates after device implantation between the NICM and ICM groups. Patients in the 2 groups had similar outcomes up to 1 year with LVAD therapy.

Conclusion: Early outcomes of LVAD therapy do not appear to be affected by heart failure etiology. Ongoing investigation is required to determine the long-term outcomes of LVAD therapy in ICM and NICM.

Systematic review registration: PROSPERO register, record ID 76483.

Contexte: Les professionnels de la santé peuvent être moins enclins à envisager un traitement à long terme par dispositif d'assistance ventriculaire gauche (DAVG) en cas d'insuffisance cardiaque terminale résultant d'une myocardiopathie non ischémique plutôt que d'une myocardiopathie ischémique, en raison du risque potentiellement accru d'atteinte du ventricule droit dans le premier cas. Cependant, on ne sait pas si la cause de l'insuffisance cardiaque a un effet clinique significatif sur les issues après l'implantation d'un DAVG. Dans cette revue systématique, nous avons voulu déterminer si l'étiologie ischémique ou non ischémique a une incidence sur les issues pour les patients.

Méthodes: Nous avons interrogé MEDLINE, Embase, PubMed et la Bibliothèque Cochrane pour trouver les études publiées en anglais entre le $1^{\text {er }}$ janvier 2000 et le 22 novembre 2018 qui examinaient la survie et le taux de greffe après l'implantation d'un DAVG chez les patients atteints d'une insuffisance cardiaque ischémique ou non ischémique. Les essais cliniques randomisés, les études de cohorte, les études castémoins, les études transversales et les séries de cas ayant un échantillon d'au moins 8 patients étaient admissibles pour inclusion. Pour qu'une publication soit incluse dans la méta-analyse, les issues à l'étude devaient comprendre au minimum les décès 
dans les 30 jours ou dans l'année suivant l'implantation du DAVG. La qualité des études retenues a été évaluée par 2 évaluateurs indépendants au moyen de l'échelle Newcastle-Ottawa pour l'évaluation de la qualité des études de cohorte. L'outil GRADE (Grading of Recommendations Assessment, Development and Evaluation) a servi à évaluer la qualité des données sur les issues (survie après 30 jours, survie après 1 an et greffe cardiaque après le traitement par DAVG) dans l'ensemble des études.

Résultats: Sur les 2843 citations recensées, 7 études respectaient tous les critères d'inclusion. Elles étaient généralement de bonne qualité, mais l'indication des caractéristiques démographiques des patients, des issues et des complications était hétérogène. Nous n'avons trouvé aucune différence significative dans la survie après 30 jours ou après 1 an, ni dans le taux de greffe cardiaque après l'implantation du dispositif entre les groupes ischémique et non ischémique. Les patients des 2 groupes avaient des issues similaires jusqu'à 1 an après le traitement par DAVG.

Conclusion: Les issues à court terme du traitement par DAVG ne semblent pas influencées par l'étiologie de l'insuffisance cardiaque. Il faudra faire d'autres études pour caractériser les issues à long terme en présence d'insuffisance cardiaque ischémique et non ischémique.

Enregistrement de la revue systématique : Registre PROSPERO, numéro 76483.

$\mathbf{T}$ he advent of continuous-flow left ventricular assist devices (LVADs), with increased reliability and fewer complications than older-generation pulsatile devices, has led to a rise in the use of LVADs for medically refractory end-stage heart failure (ESHF)., ${ }^{1,2}$ Long-term survival data are emerging in the literature as LVADs remain implanted for longer periods, with patients routinely surviving over 5 years with LVAD support. ${ }^{3-5}$ In a multicentre study of 156 patients surviving for at least 4 years on LVAD support, the mean survival duration was 7.1 years, with the majority of patients retaining good function (New York Heart Association Classification class I or III). ${ }^{5}$

Given the increasing utility of LVADs to prolong life in patients with ESHF, a better understanding of factors influencing patient outcomes following LVAD implantation becomes more important. ${ }^{6}$ Patients with ESHF as a result of ischemic cardiomyopathy (ICM) may have better longterm clinical outcomes with LVAD therapy than patients with ESHF as a result of nonischemic cardiomyopathy (NICM) owing to a typically greater degree of right ventricular involvement in the latter., ${ }^{78}$ On the other hand, patients with NICM are typically younger, with fewer comorbidities. ${ }^{9} 10$ There have been contradictory reports in the literature on outcomes following LVAD implantation in patients with NICM and those with ICM..${ }^{11,12}$

The objective of this systematic review was to determine whether there is a difference in survival and rates of patientrelevant complications with LVAD therapy between patients with ESHF as a result of NICM versus ICM.

\section{Methods}

This systematic review and meta-analysis followed the guidelines presented in the Preferred Reporting Items for Systematic Reviews and Meta-Analyses (PRISMA) State- ment. ${ }^{13}$ The study protocol is in the PROSPERO register under record ID 76483.

\section{Search strategy}

We performed a search of the MEDLINE, Embase, PubMed and Cochrane Library databases. We also conducted a grey literature search using Clinicaltrials.gov. Search results were restricted by date from Jan. 1, 2000, to the date the search was run (Nov. 22, 2018) and to articles published in English. Before 2000, the literature offered clinical data only on older-generation pulsatile LVADs, which were excluded from our study. We searched databases using the following search terms: "cardiomyopathy," "heart failure," "systolic dysfunction," "left ventricular assist device" and "continuous flow," and their variants.

\section{Study selection}

Two reviewers (C.W. and A.S.) independently screened records identified through the search using a 2 -stage strategy of an initial title and abstract review, and then a full-text review of pertinent articles identified. Disagreements were resolved through discussion and consultation with a third reviewer (C.Y.). Randomized clinical trials, cohort studies, case-control studies, cross-sectional studies and case series with a sample size of at least 8 patients were eligible for inclusion. Studies included were those that examined clinical outcomes, with mortality as a required inclusion criterion, following LVAD implantation in defined NICM and ICM patient populations. Studies that used pulsatile-flow LVADs, those in pediatric $(<18 \mathrm{yr})$ populations, and those in acute myocarditis or compaction were excluded. 


\section{Data extraction}

Two reviewers (C.W. and A.S.) independently extracted the data from included studies using a standardized form. Disagreements were resolved by review by a third reviewer (C.Y.).

To be included in the meta-analysis, outcomes had to include at least death reported at 30 days or 1 year after LVAD implantation. The other commonly reported outcome was whether patients underwent heart transplantation following LVAD therapy or continued with LVAD support as destination therapy.

Where possible, we extracted data on age, gender, certain comorbidities (diabetes, hypertension, chronic renal insufficiency, dialysis, chronic obstructive pulmonary disease, previous stroke or transient ischemic attack, peripheral arterial disease), length of stay in hospital and in the intensive care unit, and certain major complications (major bleeding, right ventricular failure, infection, stroke/ transient ischemic attack or readmission to hospital).

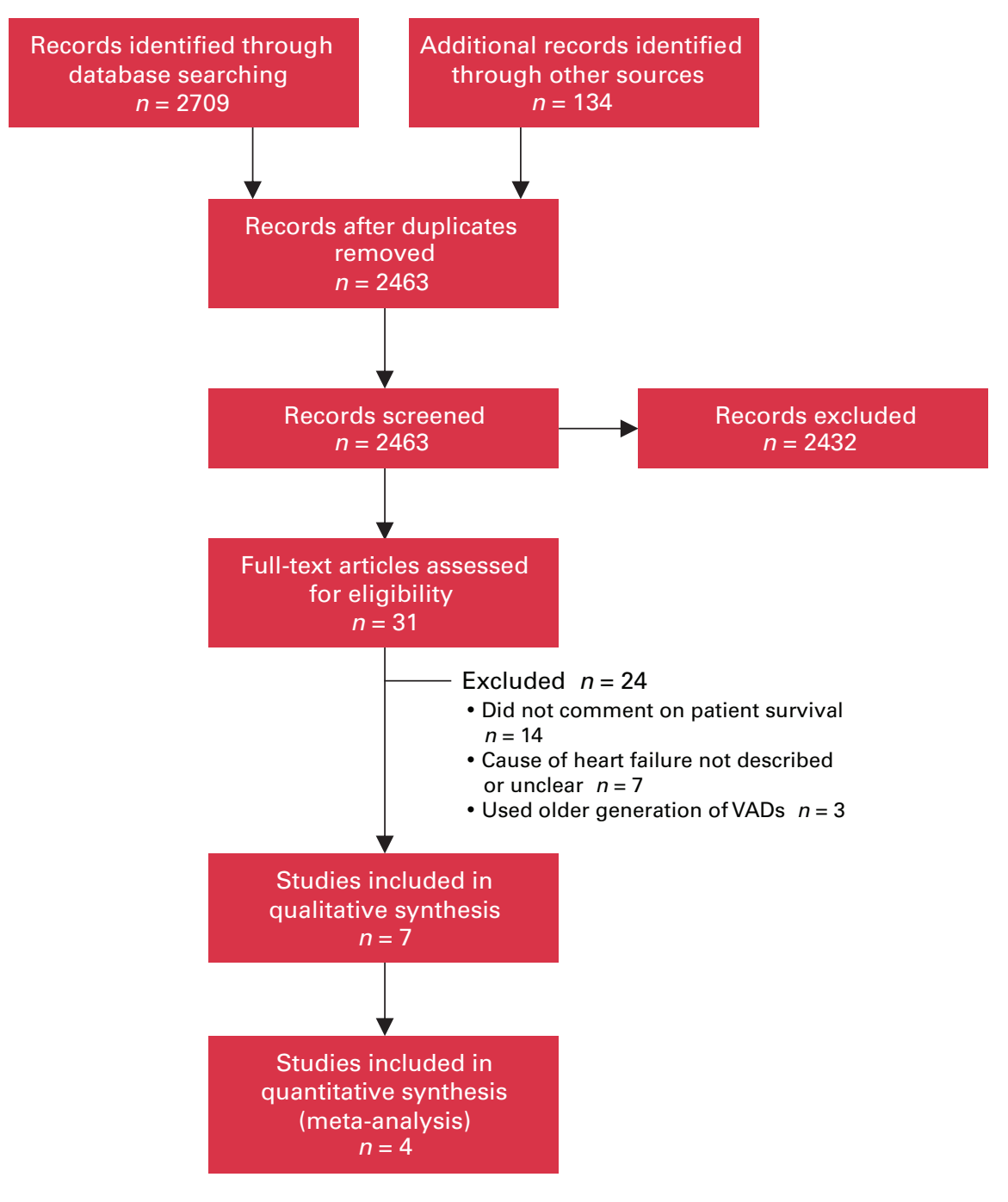

Fig. 1. Flow diagram showing study selection. $V A D=$ ventricular assist device.

\section{Quality assessment}

The quality of included studies was assessed by 2 independent reviewers (C.W. and A.S.) using the Newcastle-Ottawa Quality Assessment Scale for Cohort Studies. ${ }^{14}$ Author disclosure statements were also examined when available for financial and other conflicts of interest. The Grading of Recommendations Assessment, Development and Evaluation (GRADE) quality-assessment tool was used to assess outcomes (30-d survival, 1-yr survival and cardiac transplantation) following LVAD therapy across studies. ${ }^{15}$

\section{Statistical analysis}

All statistical analyses were performed in Stata 14.0 (StataCorp). Heterogeneity, as defined by the $I^{2}$ statistic, was determined a priori to be above the threshold for pooling at $40 \%$. In addition, studies were pooled only if the reviewers believed them to be clinically similar and did not have concerns with pooling. We summarized pooled data with descriptive statistics, using means and standard deviations with normally distributed data, and medians with interquartile ranges where necessary. When pooling was determined to be appropriate, odds ratios (ORs) and 95\% confidence intervals (CIs) were reported. We decided a priori that, owing to the expected clinical heterogeneity in studies, random-effects models would be most appropriate.

\section{Results}

Our search strategy identified 2843 citations, of which 7 met the inclusion criteria: 6 full-text manuscripts and 1 conference abstract. Our search and selection strategy is summarized in Figure 1. Agreement between reviewers on which studies to include was fair (Cohen $\kappa=0.25)$. One additional conference abstract was identified that met the inclusion criteria; however, the authors did not provide data on mortality after LVAD implantation in a usable format (only the OR was stated), and we were unable to contact the investigators. ${ }^{16}$

Characteristics of the included studies are provided in Table 1. Five studies were conducted at centres in the United States, ${ }^{11,12,17-19}$ and 2 
Table 1. Characteristics of studies included in review

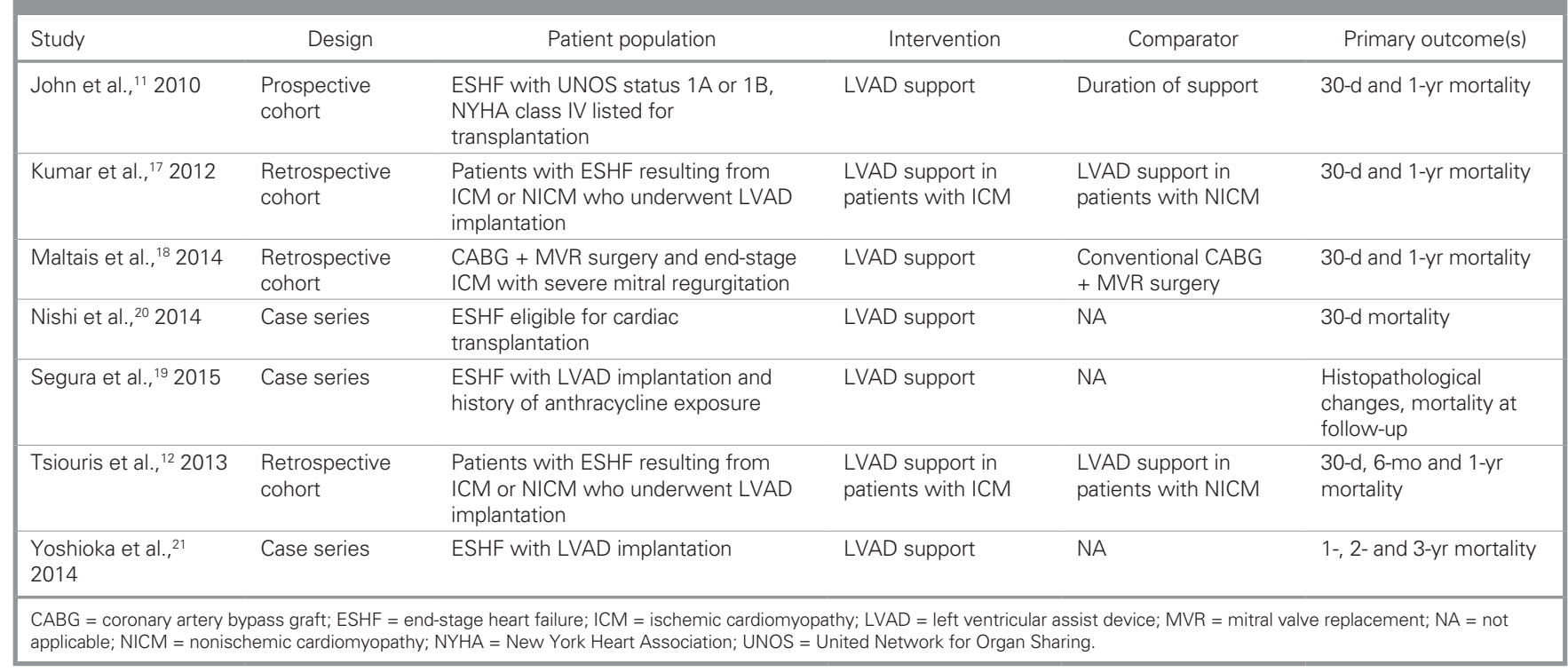

were conducted at Japanese centres. ${ }^{20,21}$ Six studies were single-centre observational studies or case series, and 1 study was a multicentre study that examined patient records from 31 centres in the US. ${ }^{11}$ The HeartMate II (Thoratec Corporation) was the most commonly used device $(96.4 \%)$, with the HeartWare (HeartWare International) (2.4\%) and Jarvik 2000 (Jarvik Heart) (1.2\%) being more rarely used. .11,12,17-21 $^{2}$

The demographic characteristics of the patient population included are summarized in Table 2, although reporting of patient demographics was heterogeneous. A total of 674 patients (mean sample size 96, median sample size 33) were enrolled across all included studies. Study sample sizes varied greatly, from 8 patients in a study reporting a singlecentre experience with LVAD therapy ${ }^{21}$ to 468 patients in a study detailing a multicentre prospective cohort trial. ${ }^{11}$ Patients had their devices implanted between 2003 and 2012.

A summary of the outcomes reported in included studies is provided in Table 3, although this reporting was also heterogeneous. Most studies were retrospective cohorts or case series that were interested primarily in rates of death and of major complications. Only John and colleagues ${ }^{11}$ reported a prospective cohort study that examined the impact of duration of LVAD support on survival rates after heart transplantation. Most studies reported mortality rates 30 days and 1 year after device implantation or transplantation. Studies typically reported whether patients underwent transplantation and also indicated whether LVAD therapy was being used as bridge-to-transplantation or destination therapy. There did not appear to be any major differences in the proportion of patients who received LVAD support as bridge-to-transplantation or destination therapy between patients with NICM and those with ICM, nor were there major differences in rates of major complications and the average length of intensive care unit and hospital stays between the 2 groups.

\section{Quality of included studies}

All included studies reported data on mortality after LVAD implantation or after implantation following LVAD support. Data included in the meta-analysis were obtained only from studies in which the authors compared mortality rates directly between NICM and ICM patient groups.

Characteristics of the patient population in the included studies tended to be fairly homogeneous. To be considered for LVAD therapy, patients had to have a diagnosis of medically intractable ESHF. Therefore, for cohort studies, we found that patient selection was adequately free of bias, with study participants being representative of the typical population that would require device support. Whether patients belonged to the NICM or ICM group was ascertained through patient records in all studies. Most studies controlled for patient age and sex, the 2 most important demographic factors that could affect study outcomes (older patients generally have worse overall outcomes, and women are at greater risk for cerebrovascular complications after LVAD implantation than men $^{22}$ ). In all cases, 30-day mortality or 1-year mortality, or both, was reported for all patients included in the studies.

Study quality as assessed with the Newcastle-Ottawa Quality Assessment Scale for Cohort Studies is shown in Table 4. Although we included the result from Kumar and colleagues ${ }^{17}$ in our review, it was not possible to complete proper quality assessment on this study because only the abstract was available to us. We therefore excluded this study from the meta-analysis since we could not be confident in its quality.

All included studies with the exception of that of Segura and colleagues ${ }^{19}$ had a published disclosure statement. In 
the study by John and colleagues, ${ }^{11}$ which examined posttransplantation survival following LVAD support with HeartMate II devices, 3 of 11 investigators disclosed previous financial support from the manufacturer. In the study by Maltais and colleagues, ${ }^{18}$ the principal investigator disclosed previous financial support from the company that manufactures the device used in their study. None of the authors of the other studies reported potential conflicts of interest. It was not possible to determine whether any disclosures were reported by Kumar and colleagues. ${ }^{17}$

\section{Evidence synthesis}

From data sets obtained from the studies included, we were able to perform a meta-analysis of 30-day $\left(I^{2}=21 \%\right)$ and 1 -year $\left(I^{2}=38 \%\right)$ survival, as well as likelihood of undergoing transplantation $\left(I^{2}=4 \%\right)$ for patients with NICM versus ICM. Owing to the heterogeneity in the data presented by each study, only data from 3 studies could be included for each analysis.

We first examined differences in survival after LVAD implantation in patients with NICM versus ICM. Data included in this analysis were from John and colleagues ${ }^{11}$ and Tsiouris and colleagues. ${ }^{12}$ Despite observing a trend of increased survival in patients with NICM, we did not find significant differences in survival rates between the 2 patient groups 30 days (Fig. 2A) (OR 1.82, 95\% CI 0.67-4.97) and 1 year (Fig. 2B) (OR 1.00, 95\% CI 0.47-2.12) after LVAD implantation. Interestingly, Kumar and colleagues ${ }^{17}$ observed a trend toward increased survival in patients with NICM at both 30 days and 1 year after device implantation, and Tsiouris and colleagues ${ }^{12}$ observed a trend toward increased survival in patients

\begin{tabular}{|c|c|c|c|c|}
\hline \multirow[b]{2}{*}{ Characteristic } & \multicolumn{2}{|c|}{ Nonischemic cardiomyopathy } & \multicolumn{2}{|c|}{ Ischemic cardiomyopathy } \\
\hline & $\begin{array}{l}\text { No. of studies } \\
\text { reporting }\end{array}$ & $\begin{array}{l}\text { Range across } \\
\text { studies, \%* }\end{array}$ & $\begin{array}{l}\text { No. of studies } \\
\text { reporting }\end{array}$ & $\begin{array}{l}\text { Range across } \\
\text { studies, \%* }\end{array}$ \\
\hline Age, yr & 5 & $33.5-53.9$ & 4 & $59.5-73$ \\
\hline Male sex & 5 & $25-86$ & 4 & $0-85$ \\
\hline Length of follow-up, $d$ & 4 & $143-426$ & 3 & $152-414$ \\
\hline \multicolumn{5}{|l|}{ Comorbidities } \\
\hline Diabetes & 2 & $8-30$ & 2 & $18-74$ \\
\hline Hypertension & 2 & $8-85$ & 1 & 91 \\
\hline Chronic renal insufficiency & 3 & $11-29$ & 3 & $0-70$ \\
\hline Dialysis & 1 & 2 & 1 & 6 \\
\hline $\begin{array}{l}\text { Chronic obstructive } \\
\text { pulmonary disease }\end{array}$ & 1 & 12 & 1 & 32 \\
\hline $\begin{array}{l}\text { Previous stroke/transient } \\
\text { ischemic attack }\end{array}$ & 1 & 17 & 0 & 12 \\
\hline Peripheral arterial disease & 1 & 11 & 1 & \\
\hline History of cardiac surgery & 4 & $10-14$ & 3 & $43-100$ \\
\hline Creatinine level, mg/dL & 3 & $0.8-1.35$ & 2 & $0.8-1.49$ \\
\hline Mechanically ventilated & 1 & 3 & 1 & 9 \\
\hline
\end{tabular}

\begin{tabular}{|c|c|c|c|c|c|c|}
\hline \multirow[b]{2}{*}{ Outcome } & \multicolumn{3}{|c|}{ Nonischemic cardiomyopathy } & \multicolumn{3}{|c|}{ Ischemic cardiomyopathy } \\
\hline & $\begin{array}{l}\text { No. of studies } \\
\text { reporting }\end{array}$ & $\begin{array}{c}\text { Total } \\
\text { patients } \\
\text { included }\end{array}$ & $\begin{array}{l}\text { Range } \\
\text { across } \\
\text { studies }\end{array}$ & $\begin{array}{l}\text { No. of } \\
\text { studies } \\
\text { reporting }\end{array}$ & $\begin{array}{c}\text { Total } \\
\text { patients } \\
\text { included }\end{array}$ & $\begin{array}{l}\text { Range } \\
\text { across } \\
\text { studies }\end{array}$ \\
\hline \multicolumn{7}{|l|}{ Survival } \\
\hline $30 \mathrm{~d}$ & 6 & 258 & $85-100$ & 5 & 198 & $83-100$ \\
\hline $6 \mathrm{mo}$ & 4 & 94 & $89-100$ & 2 & 35 & $85-100$ \\
\hline $1 \mathrm{yr}$ & 6 & 258 & $64-100$ & 5 & 198 & $61-100$ \\
\hline Latest reported survival, yr & 4 & 171 & $1.5-4.4$ & 2 & 108 & $1.1-1.7$ \\
\hline Underwent transplantation & 6 & 258 & $11-100$ & 5 & 198 & $0-100$ \\
\hline Destination therapy & 5 & 192 & $0-89$ & 4 & 164 & $0-100$ \\
\hline Explanted/recovery & 5 & 192 & $0-25$ & 4 & 164 & $0-0$ \\
\hline \multicolumn{7}{|l|}{ Length of stay, $d$} \\
\hline Intensive care unit admission & 2 & 73 & $5.0-11.5$ & 2 & 35 & $3.0-13.0$ \\
\hline Hospital admission & 2 & 75 & $21.3-68.4$ & 2 & 67 & $18.0-24.9$ \\
\hline \multicolumn{7}{|l|}{ Complications } \\
\hline Major bleeding & 2 & 75 & $5-11$ & 2 & 67 & $15-64$ \\
\hline Right ventricular failure & 3 & 82 & $11-14$ & 1 & 34 & 9 \\
\hline Infection & 3 & 82 & $14-22$ & 2 & 67 & $12-24$ \\
\hline $\begin{array}{l}\text { Stroke/transient ischemic } \\
\text { attack }\end{array}$ & 3 & 82 & $14-22$ & 3 & 68 & $12-24$ \\
\hline Readmission & 2 & 73 & $26-29$ & 1 & 34 & 21 \\
\hline
\end{tabular}

with NICM at 1 year. However, John and colleagues ${ }^{11}$ observed slightly increased survival in patients with ICM at both 30 days and 1 year after implantation.

In addition, we did not identify any significant differences in risk of transplantation after LVAD implantation between patients with NICM and those with ICM (Fig. 3) (OR 0.47, 95\% CI 0.16-1.39). Data included in this analysis were from Tsiouris and colleagues ${ }^{12}$ and Yoshioka and colleagues. ${ }^{21}$ The latter observed a trend 
Table 4. Quality of included studies as assessed with the Newcastle-Ottawa Quality Assessment Scale for Cohort Studies ${ }^{14 *}$

\begin{tabular}{|c|c|c|c|c|c|c|c|}
\hline \multirow[b]{2}{*}{ Study } & \multicolumn{3}{|c|}{ Selection } & \multirow[b]{2}{*}{ Comparability } & \multicolumn{3}{|c|}{ Outcome } \\
\hline & $\begin{array}{l}\text { Representativeness } \\
\text { of exposed cohort }\end{array}$ & $\begin{array}{c}\text { Selection of } \\
\text { nonexposed cohort }\end{array}$ & $\begin{array}{l}\text { Ascertainment } \\
\text { of exposure }\end{array}$ & & $\begin{array}{l}\text { Assessment of } \\
\text { outcome }\end{array}$ & $\begin{array}{l}\text { Duration of } \\
\text { follow-up }\end{array}$ & $\begin{array}{l}\text { Completeness } \\
\text { of follow-up }\end{array}$ \\
\hline John et al., $2010^{11}$ & $\star$ & $\star$ & $\star$ & $\star \star$ & $\star$ & $\star$ & $\star$ \\
\hline \multicolumn{8}{|l|}{$\begin{array}{l}\text { Kumar et al., } \\
2012^{17}\end{array}$} \\
\hline $\begin{array}{l}\text { Maltais et al., } \\
2014^{18}\end{array}$ & $\star$ & $\star$ & $\star$ & $\star \star$ & $\star$ & $\star$ & $\star$ \\
\hline Nishi et al., $2014^{20}$ & & & $\star$ & & $\star$ & $\star$ & $\star$ \\
\hline $\begin{array}{l}\text { Segura et al., } \\
2015^{19}\end{array}$ & & & $\star$ & & $\star$ & $\star$ & $\star$ \\
\hline $\begin{array}{l}\text { Tsiouris et al., } \\
2013^{12}\end{array}$ & $\star$ & $\star$ & $\star$ & $\star$ & $\star$ & $\star$ & $\star$ \\
\hline $\begin{array}{l}\text { Yoshioka et al., } \\
2014^{21}\end{array}$ & & & $\star$ & & $\star$ & $\star$ & $\star$ \\
\hline
\end{tabular}

A

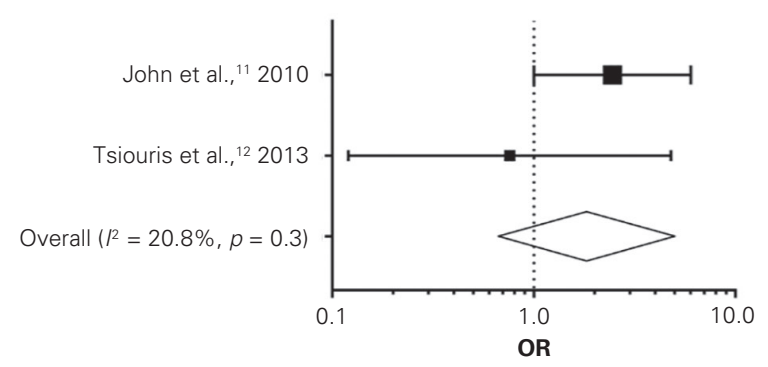

\begin{tabular}{cccc} 
OR $(\mathbf{9 5 \%} \mathbf{C l})$ & $\begin{array}{c}\text { Treatment } \\
\text { events }\end{array}$ & $\begin{array}{c}\text { Control } \\
\text { events }\end{array}$ & Weight, \% \\
\hline $2.46(1.00-6.02)$ & $100 / 107$ & $122 / 143$ & 74.4 \\
& & & \\
$0.76(0.12-4.79)$ & $32 / 34$ & $63 / 66$ & 25.6 \\
& & & \\
$1.82(0.67-4.97)$ & $132 / 141$ & $185 / 209$ & 100.0
\end{tabular}

B

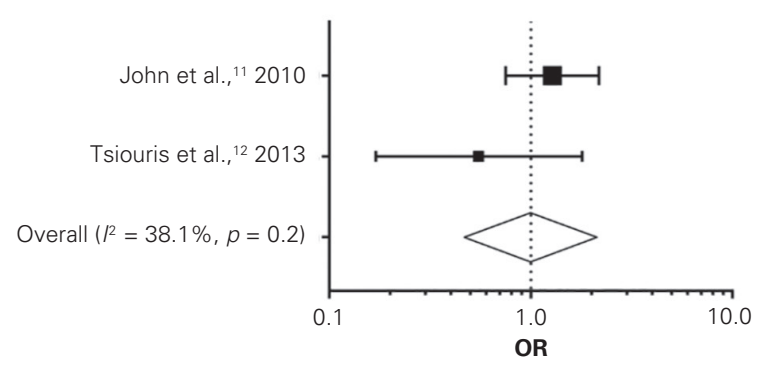

\begin{tabular}{cccc} 
OR (95\% Cl) & $\begin{array}{c}\text { Treatment } \\
\text { events }\end{array}$ & $\begin{array}{c}\text { Control } \\
\text { events }\end{array}$ & Weight, $\%$ \\
\hline $1.28(0.75-2.18)$ & $74 / 107$ & $91 / 143$ & 70.5 \\
$0.55(0.17-1.80)$ & $28 / 34$ & $59 / 66$ & 29.5 \\
$1.00(0.47-2.12)$ & $102 / 141$ & $150 / 209$ & 100.0
\end{tabular}

Favours ICM Favours NICM

Fig. 2. Patient survival following implantation of left ventricular assist devices 30 days after implantation (A) and 1 year after implantation (B). Forest plots summarize available data from studies included in the review presented as ischemic cardiomyopathy (ICM) (treatment) versus nonischemic cardiomyopathy (NICM) (control).

toward more frequent transplantation in the NICM group, but this was not significant, even in their single study. John and colleagues ${ }^{11}$ specifically examined survival in patients who had undergone LVAD implantation and subsequently transplantation, so all patients in their study underwent transplantation and could not be included in the analysis of differences in transplantation rates.

\section{Discussion}

Heart transplantation continues to be the gold standard treatment for patients with medically refractory ESHF. However, the availability of donor organs continues to be limited. Furthermore, some patients are deemed ineligible for transplantation. Durable LVAD support 


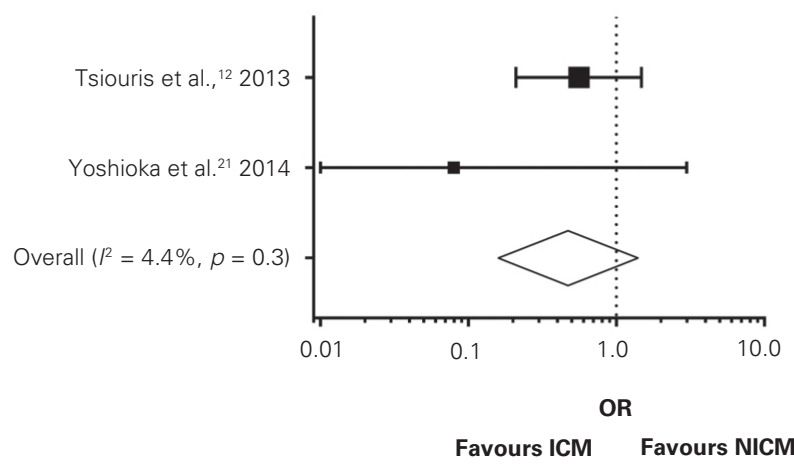

\begin{tabular}{cccc} 
OR (95\% Cl) & $\begin{array}{c}\text { Treatment } \\
\text { events }\end{array}$ & $\begin{array}{c}\text { Control } \\
\text { events }\end{array}$ & Weight, \% \\
\hline $0.56(0.21-1.48)$ & $7 / 34$ & $21 / 66$ & 91.4 \\
$0.08(0.01-2.99)$ & $0 / 1$ & $6 / 7$ & 8.6 \\
& & & \\
$0.47(0.16-1.39)$ & $7 / 35$ & $27 / 73$ & 100.0
\end{tabular}

Fig. 3. Rates of cardiac transplantation following implantation of left ventricular assist devices. Forest plot summarizes available data from studies included in the review presented as ischemic cardiomyopathy (ICM) (treatment) versus nonischemic cardiomyopathy (NICM) (control).

has emerged as a viable strategy for both bridge-totransplantation and destination therapy. Despite the predicted increase in LVAD use, very little is known about the impact of the cause of heart failure on outcomes following LVAD therapy. Etiology could reasonably be expected to have a substantial impact on outcomes owing to the observation that ICM typically affects the left ventricle more significantly, whereas NICM more typically shows biventricular involvement. Clinicians may therefore be somewhat more reluctant to offer long-term LVAD therapy in patients with NICM. On a cellular level, the cause of heart failure appears to be important in cardiomyocyte remodelling. Wever-Pinzon and colleagues $^{23}$ showed significant improvements in left ventricular ejection fraction for both patients with ICM and those with NICM following LVAD support. However, only $5 \%$ of patients with ICM achieved a left ventricular ejection fraction greater than $40 \%$, compared to $21 \%$ of patients with NICM.

There are conflicting reports on the impact of the cause of heart failure on the outcome of LVAD therapy. In a study among 100 patients with ICM or NICM, mortality rates following device implantation were not significantly different between the 2 groups. ${ }^{12}$ In contrast, Kumar and colleagues ${ }^{17}$ reported that ICM was an independent predictor of death after LVAD implantation. The matter is further complicated by limited duration of follow-up and small samples, which makes it difficult to determine whether the cause of ESHF has a significant impact on patient outcomes following LVAD therapy over a longer period. It is possible that the subtype of NICM played a role in some of the inconsistencies that we observed in our meta-analysis. Neither Tsiouris and colleagues ${ }^{12}$ nor John and colleagues ${ }^{11}$ reported the specific cause in their NICM cohorts, which made it impossible to determine whether NICM subtype had any affect on outcomes.

Following the considerations on evidence quality put forward by the GRADE Working Group, ${ }^{15}$ we found no difference in survival rates between ICM and NICM 30 days and 1 year after LVAD implantation. This allows us to make a very weak conclusion that the cause of ESHF does not have a substantial impact on shortand medium-term survival and cardiac transplantation rates following LVAD implantation. Table 5 presents a GRADE evidence profile of the 3 major outcomes examined in this meta-analysis (30-d survival, 1-yr survival and cardiac transplantation). Given that patients with NICM may be expected to have slightly worse outcomes than those with ICM because of a greater degree of right ventricular involvement in the former population, ${ }^{7,8}$ it was surprising to see no differences in survival at 30 days or 1 year. If more high-quality data had been available, it is possible that this prediction would have been borne out, but it is also possible that any expected survival benefit for patients with ICM who have LVAD support is offset by the fact that these patients tend to be older and have more comorbidities. ${ }^{9,10}$ In addition, although we did not formally include recovery of left ventricular function as an outcome in our review, it should be noted that only 1 of the 7 studies included reported left ventricular recovery. ${ }^{19}$ In that study, 3 of 12 patients were reported to have recovery of left ventricular function and device explantation.

\section{Limitations}

Our study is limited by a small sample size, differences in causes of NICM, the older age of the ICM group and an absence of any randomized controlled trials available to be included in the analysis. Another major limitation is the 
Table 5. Grading of Recommendations Assessment, Development and Evaluation (GRADE) evidence profile for use of left ventricular assist device therapy in patients with end-stage heart failure resulting from ischemic or nonischemic cardiomyopathy

\begin{tabular}{|c|c|c|c|c|c|c|c|c|c|}
\hline \multirow[b]{2}{*}{$\begin{array}{l}\text { Outcome; no. of } \\
\text { studies (no. of } \\
\text { participants) }\end{array}$} & \multicolumn{5}{|c|}{ Quality assessment } & \multicolumn{4}{|c|}{ Summary of findings } \\
\hline & $\begin{array}{c}\text { Study } \\
\text { limitations* }\end{array}$ & Consistency $\dagger$ & Directness & Precision $\ddagger$ & $\begin{array}{c}\text { Publication } \\
\text { bias }\end{array}$ & OR $(95 \% \mathrm{Cl})$ & $\begin{array}{l}\text { Best } \\
\text { estimate of } \\
\text { ICM group } \\
\text { rate, \% }\end{array}$ & $\begin{array}{c}\text { Best } \\
\text { estimate of } \\
\text { NICM group } \\
\text { rate, \% }\end{array}$ & Quality \\
\hline \multicolumn{10}{|l|}{ 30-d survival } \\
\hline $2(350)$ & $\begin{array}{l}\text { Serious } \\
\text { limitations }\end{array}$ & $\begin{array}{l}\text { Explainable } \\
\text { heterogeneity }\end{array}$ & Direct & Imprecision & Unlikely & $1.82(0.67-4.97)$ & 79.6 & 88.9 & Very low \\
\hline \multicolumn{10}{|l|}{ 1-yr survival } \\
\hline $2(350)$ & $\begin{array}{l}\text { Serious } \\
\text { limitations }\end{array}$ & $\begin{array}{l}\text { Explainable } \\
\text { heterogeneity }\end{array}$ & Direct & Imprecision & Unlikely & $1.00(0.47-2.12)$ & 72.5 & 72.7 & Very low \\
\hline \multicolumn{10}{|l|}{ Transplantation } \\
\hline 2 (108) & $\begin{array}{l}\text { Serious } \\
\text { limitations }\end{array}$ & $\begin{array}{l}\text { Explainable } \\
\text { heterogeneity }\end{array}$ & Direct & Imprecision & Unlikely & $0.47(0.16-1.39)$ & 20.0 & 37.0 & Very low \\
\hline $\begin{array}{l}\mathrm{Cl}=\text { confidence inte } \\
{ }^{*} \text { Observational stud } \\
\text { †One study examin } \\
\text { ‡Confidence interva }\end{array}$ & $\begin{array}{l}\text { ICM = ischen } \\
\text { nly (randomiz } \\
\text { utcomes follov } \\
\text { udes possible }\end{array}$ & $\begin{array}{l}\text { cardiomyopathy; } \\
\text { ontrolled trials un } \\
\text { cardiac transplan } \\
\text { vival advantage fr }\end{array}$ & $\begin{array}{l}\mathrm{U}=\text { nonische } \\
\text { lable). } \\
\text { on only; anot } \\
\text { use of left ve }\end{array}$ & $\begin{array}{l}\text { cardiomyopat } \\
\text { sed a differe } \\
\text { ular assist de }\end{array}$ & $\begin{array}{l}\mathrm{R}=\text { odds ra } \\
\text { tinuous-flov } \\
\text { both patie }\end{array}$ & $\begin{array}{l}\text { ventricular assist de } \\
\text { oups. }\end{array}$ & model from & t used in the oth & r studies. \\
\hline
\end{tabular}

very small number of studies that were usable for our metaanalysis, owing to limitations in how authors reported their outcomes in the studies that met the inclusion criteria. As more and longer-term outcomes following LVAD support are published, sample sizes for review will increase, which will help mitigate these limitations with statistical analysis. In addition, third-generation centrifugal continuous-flow pumps are beginning to be used clinically, with promising early results. ${ }^{24}$ The recently published MOMENTUM 3 trial showed that the HeartMate 3 - a magnetically levitated centrifugal pump - had a higher rate of survival free of disabling strokes and reoperation or pump removal at 6 months (hazard ratio $0.46,95 \%$ CI $0.31-0.69$ ) and at 2 years, and a lower rate of pump thrombosis than the older HeartMate II axial flow pumps. ${ }^{25}$ However, studies comparing outcomes in NICM versus ICM with these nextgeneration centrifugal-flow LVADs are still pending. Although LVADs may be on track to compete with heart transplantation, ${ }^{26}$ we are still far from the equipoise required to conduct a randomized controlled trial in this patient population. It is therefore relevant for future investigators to investigate and report the impact of specific causes of heart failure on patient outcomes over a longer period.

\section{Conclusion}

As LVADs for destination therapy become commonplace, a more comprehensive understanding of the impact of the cause of heart failure on patient outcomes following LVAD therapy over longer periods is necessary to inform decision-making. Although our findings suggest that there are no differences in short- or medium-term outcomes after LVAD therapy in patients with ICM versus NICM, the paucity of data beyond 1 year highlights the need for studies examining long-term patient outcomes following LVAD therapy.
Affiliations: From the Division of Cardiac Surgery, Department of Surgery, Schulich School of Medicine and Dentistry, Western University, London, Ont. (Wavell, Sokolowski, Yin); The Hospital for Sick Children, Toronto, Ont. (Klingel); Department of Microbiology and Immunology, Schulich School of Medicine and Dentistry, Western University, London, Ont. (Yin); and the Division of Critical Care Medicine, Department of Medicine, Schulich School of Medicine and Dentistry, Western University, London, Ont. (Nagpal).

Competing interests: None declared.

Contributors: C. Wavell and A. Sokolowski contributed equally to this work. C. Yin, M. Klingel and D. Nagpal designed the study. C. Wavell and A. Sokolowski acquired the data, which all authors analyzed. C. Wavell, A. Sokolowski and C. Yin wrote the manuscript, which M. Klingel and D. Nagpal critically revised. All authors gave final approval of the article to be published.

Content licence: This is an Open Access article distributed in accordance with the terms of the Creative Commons Attribution (CC BYNC-ND 4.0) licence, which permits use, distribution and reproduction in any medium, provided that the original publication is properly cited, the use is noncommercial (i.e., research or educational use), and no modifications or adaptations are made. See: https://creativecommons. org/licenses/by-nc-nd/4.0/

\section{References}

1. Kirklin JK, Pagani FD, Kormos RL, et al. Eighth annual INTERMACS report: special focus on framing the impact of adverse events. 7 Heart Lung Transplant 2017;36:1080-6.

2. Birks EJ. The promise of recovery. 7ACC Heart Fail 2016;4:577-9.

3. Schmitto JD, Hanke JS, Rojas SV, et al. First implantation in man of a new magnetically levitated left ventricular assist device (HeartMate III). 7 Heart Lung Transplant 2015;34:858-60.

4. McIlvennan CK, Magid KH, Ambardekar AV, et al. Clinical outcomes after continuous-flow left ventricular assist device: a systematic review. Circ Heart Fail 2014;7:1003-13.

5. Gosev I, Kiernan MS, Eckman P, et al. Long-term survival in patients receiving a continuous-flow left ventricular assist device. Ann Thorac Surg 2018;105:696-701.

6. Smedira NG, Hoercher KJ, Yoon DY, et al. Bridge to transplant experience: factors influencing survival to and after cardiac transplant. 7 Thorac Cardiovasc Surg 2010;139:1295-305, 1305.e1-4.

7. Boulate D, Marques MA, Ha R, et al. Biventricular VAD versus LVAD for right heart failure. Ann Cardiothorac Surg 2014;3:585-8. 
8. Sabe SA, Charoensri N, Sabe MA, et al. Predictors of right ventricular ejection fraction in patients with nonischemic cardiomyopathy. 7 Cardiovasc Magn Reson 2016;18:297.

9. Corbalan R, Bassand JP, Illingworth L, et al. Analysis of outcomes in ischemic vs nonischemic cardiomyopathy in patients with atrial fibrillation. 7AMA Cardiol 2019;4:526-48.

10. Streitner F, Herrmann T, Kuschyk J, et al. Impact of shocks on mortality in patients with ischemic or dilated cardiomyopathy and defibrillators implanted for primary prevention. PLoS One 2013;8:1-7.

11. John R, Pagani FD, Naka Y, et al. Post-cardiac transplant survival after support with a continuous-flow left ventricular assist device: impact of duration of left ventricular assist device support and other variables. 7 Thorac Cardiovasc Surg 2010;140:174-81.

12. Tsiouris A, Borgi J, Karam J, et al. Ischemic versus nonischemic dilated cardiomyopathy: the implications of heart failure etiology on left ventricular assist device outcomes. ASAIO 7 2013;59:130-5.

13. Moher D, Liberati A, Tetzlaff J, et al.; PRISMA Group. Preferred reporting items for systematic reviews and meta-analyses: the PRISMA statement. PLoS Med 2009;6:e1000097.

14. Wells GA, Shea B, O'Connell D, et al. The Newcastle-Ottawa Scale (NOS) for assessing the quality of nonrandomised studies in meta-analyses. Ottawa: Ottawa Hospital Research Institute; 2009. Available: www.ohri.ca/programs/clinical_epidemiology/oxford.asp (accessed 2018 Oct. 1).

15. Guyatt GH, Oxman AD, Vist GE, et al.; GRADE Working Group. What is "quality of evidence" and why is it important to clinicians? BM7 2008;336:995-8.

16. Sharma R, Prabhu S, Jones K, et al. Comparing outcomes in patients with ischaemic and non-ischaemic cardiomyopathy requiring left ventricular assist device support - a single centre experience. Heart Lung Circ 2012;21:S77.
17. Kumar S, Ward C, Taghavi S, et al. Outcomes of LVAD insertion in ischemic vs non-ischemic cardiomyopathy patients. 7 Card Fail 2012; $18: S 44$.

18. Maltais S, Tchantchaleishvili V, Schaff HV, et al. Management of severe ischemic cardiomyopathy: left ventricular assist device as destination therapy versus conventional bypass and mitral valve surgery. 7 Thorac Cardiovasc Surg 2014;147:1246-50.

19. Segura AM, Radovancevic R, Demirozu ZT, et al. Anthracycline treatment and ventricular remodeling in left ventricular assist device patients. Tex Heart Inst 7 2015;42:124-30.

20. Nishi H, Toda K, Miyagawa S, et al. Initial experience in Japan with HeartWare ventricular assist system. 7 Artif Organs 2014;17:149-56.

21. Yoshioka D, Matsumiya G, Toda K, et al. Clinical results with Jarvik 2000 axial flow left ventricular assist device: Osaka University experience. 7 Artif Organs 2014;17:308-14.

22. Hsich EM, Naftel DC, Myers SL, et al. Should women receive left ventricular assist device support? Findings from INTERMACS. Circ Heart Fail 2012;5:234-40.

23. Wever-Pinzon J, Selzman CH, Stoddard G, et al. Impact of ischemic heart failure etiology on cardiac recovery during mechanical unloading. 7 Am Coll Cardiol 2016;68:1741-52.

24. Mehra MR, Naka Y, Uriel N, et al. A fully magnetically levitated circulatory pump for advanced heart failure. NEngl F Med 2016;376:440-50.

25. Mehra MR, Goldstein DJ, Uriel N, et al. Two-year outcomes with a magnetically levitated cardiac pump in heart failure. $N$ Engl 7 Med 2018;378:1386-95.

26. Kirklin JK, Naftel DC, Pagani FD, et al. Long-term mechanical circulatory support (destination therapy): On track to compete with heart transplantation? 7 Thorac Cardiovasc Surg 2012;144:584-603, discussion 597-8. 